\title{
UREMIC PRURITUS AND ASSOCIATED FACTORS IN CHRONIC DIALYSIS PATIENTS: AN OBSERVATIONAL STUDY IN WESTERN NEPAL
}

\author{
Kumar $A^{1^{*}}$, Subedi $S^{2}$, Maskey $A^{3}, A \operatorname{sim} M^{4}$, Sathian $B^{5}$, Neupane $D^{6}$
}

\section{Affiliation}

1. Associate Professor, Department of Dermatology, Manipal college ofmedical sciences, Pokhara, Nepal

2. Lecturer, Department of Dermatology, Gandaki Medical College, Pokhara, Nepal

3. Associate Professor, Department of Nephrology, Manipal college of medical sciences, Pokhara, Nepal

4. Reserch assistant, Trauma Surgery, Surgery Department, Hamad General Hospital, Qatar

5. Scientist, Geriatric Medicine Department, Rumailah Hospital, Hamad Medical Corporation, Qatar

6. Resident, Department of Dermatology, Manipal College of Medical Sciences, Pokhara, Nepal

\section{ARTICLE INFO}

Received : 28 September, 2020

Accepted : 26 November, 2020

Published : 22 December, 2020

(C) Authors retain copyright and grant the journal right of first publication with the work simultaneously licensed under Creative Commons Attribution License CC - BY 4.0 that allows others to share the work with an acknowledgment of the work's authorship and initial publication in this journal.

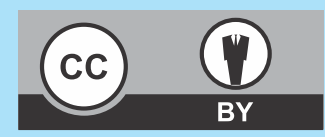

\section{ORA 212}

DOI: https://doi.org/10.3126/bjhs.v5i3.33703

$$
\begin{gathered}
\text { * Corresponding Author } \\
\text { Dr. Ajay Kumar } \\
\text { Associate Professor } \\
\text { Department of Dermatology } \\
\text { Manipal College of Medical Sciences, Pokhara, Nepal } \\
\text { Email ID: drajayk2002@yahoo.com } \\
\text { ORCID ID: https://orcid.org/0000-0002-4900-055X }
\end{gathered}
$$

\section{Citation}

Kumar A, Subedi S, Maskey A, Asim M, Sathian B, Neupane D., Uremic Pruritus And Associated Factors In Chronic Dialysis Patients: An Observational Study In Western Nepal. BJHS 2020;5(3)13. 1224-1230.

\section{ABSTRACT}

\section{Introduction}

Pruritus is one of the well-recognized major skin derangements in patients with advanced renal failure and are usually without visible skin lesions. Only few studies have addressed this issue in Nepalese population.

\section{Objective}

The present study aims to identify the prevalence and associated factors of uremic pruritus in chronic dialysis patients in western Nepal.

\section{Methodology}

A prospective observational study was conducted to include all chronic dialysis patients with uremic pruritus at the Manipal Teaching Hospital, Pokhara, Nepal over a period of one year (June 2018 and May 2019).

\section{Result}

During the study period, a total of 59 patients were included in the study with mean age of $55.8 \pm 15.8$ years, of which 37 (63\%) patients developed uremic pruritus.

Statistically significant relationship between presence of pruritus and pruritus severity with frequency of itching grade and sleep disturbance score among elderly $(p=0.001)$ were observed

The serum urea can predict uremic pruritus among elderly patients with a good diagnostic value. The multivariate analysis showed male gender, hypertension, elevated serum albumin and random blood sugar were independent predictors of pruritus in patients undergoing chronic dialysis.

\section{Conclusions}

Our findings demonstrate that higher proportion of patients undergoing chronic dialysis were diagnosed with uremic pruritus (63\%) and occurrence of pruritus had association with frequency of itching grade and sleep disturbance score. The serum levels of urea may predict the occurrence of pruritus among elderly patients. Further more, a large multicenter study is warranted with longer follow up which may provide robust information on the burden of pruritus and its associated factors to guide appropriate management among elderly.

\section{KEYWORDS}

uremic pruritus, chronic kidney diseases, dialysis, risk factors 


\section{INTRODUCTION}

Pruritus is one of the well-recognized major skin derangements in patients with advanced renal failure and is usually identified without visible skin lesions. ${ }^{1,2}$ Other cutaneous manifestations of patients on dialysis are xerosis, hyper pigmentation, reactive perforating collagenosis, mucosal, hair and nail changes. An earlier study reported the global prevalence of uremic pruritus (moderate or extreme) to be $42 \%$, and also suggested asignificant association of uremic pruritus with depression, sleeping disorders, impaired quality of life and death. ${ }^{3}$ In Nepal, the prevalence of pruritus among chronic kidney disease patients undergoing dialysis was estimated to be $40-55 \%$.

Even though since long time evidence exists for the relationship between chronic renal failure and pruritus, its molecular basis remains controversial, considering the subjective nature and strong influence of psychological factors. ${ }^{6}$ Also, there is paucity of information on the prevalence of uremic pruritus in chronic kidney disease patients from the western part of Nepal. Therefore, the present study aims to identify the prevalence and associated factors of uremic pruritus in chronic dialysis patients in western Nepal, with specific focus on the elderly population in Nepal.

\section{METHODOLOGY}

This prospective observational study was conducted to include all chronic dialysis patients with uremic pruritus at the Manipal Teaching Hospital, Pokhara, Nepal over a period of one year (June 2018 and May 2019). Patients with pruritus due to some other dermatological disorders and those who refused to participate in the study were excluded.

Uremic pruritus was considered, if it last for more than three months among dialysis patients, and was quantified with the help of visual analogue scale (VAS). It is a 10-point scale instrument in which 0 refers to no pruritus while 10 point is suggestive of very severe pruritus. The participants responded to the VAS questionnaire based on the previous four weeks status.

Study population included all chronic dialysis patients underwent peritoneal as well as hemodialysis. Ethical approval was obtained from the institutional review board before the study conduction. The purpose of the study was explained to the participants by study investigators and those who agreed for participation provided the written informed consent. Subjects who were not willing to participate in the study were excluded.

Data included patient characteristics (age, gender, body mass index), comorbidities (hypertension, diabetes mellitus), biochemical parameters (Hemoglobin, serum urea, creatinine, albumin, calcium, phosphate, and random glucose), type of dialysis (hemodialysis /peritoneal), pruritus status (present or absent, localized/generalized); Visual analog scale [no pruritus (VAS $=0$ ), mild pruritus (VAS $=1-2$ ), moderate pruritus (VAS= 3-6), severe pruritus (VAS= 7-8)]; Sleep Disturbance Score (sleep never disturbed due to pruritus, occasionally delays falling asleep, frequent delays in falling asleep, delayed falling asleep and occasionally awakes at night, and delayed falling asleep and frequently awakes at night); frequency of itching score [no pruritus, 4short episodes (less than $10 \mathrm{~min}$ ), one long episode (more than $10 \mathrm{~min}$ ) and persistent pruritus] and treatment (antipruritic treatments and other treatments/supplements).

\section{Statistical analysis}

Data were presented as proportions, medians (minimummaximum range), or mean ( \pm standard deviation; SD) as appropriate. Study variables were analyzed and compared according to pruritus status (Pruritus present vs. Pruritus not present) in the overall patients as well as among elderly patients. Differences between categorical variables were analyzed using the Chi-square or Fisher's exact test, whereas Student's t test was performed to compare continuous variables, whenever applicable. Receiver operating characteristic (ROC) curve was used to determine the cutoff value for serum urea for predicting the uremic pruritus in elderly patients. The area under the curve (AUC) was used to compare the discriminatory power of the serum urea with an AUC of 1.0 considered as perfect discrimination and 0.5 considered as equal to chance. The sensitivity, specificity, positive predictive value (PPV), negative predictive value (NPV), positive likelihood ratio, negative likelihood ratio and accuracy of the serum urea in predicting the uremic pruritus were determined. The multivariate logistic regression analysis was conducted to determine the factors associated with pruritus development in the overall patients as well as among elderly group. Two-tailed $p$ value $<0.05$ was considered statistically significant. Data analysis was carried out using IBM SPSS Statistics for Windows, Version 21.0. Armonk, NY, USA.

\section{RESULTS}

During the study period, a total of 59 patients were included in the study. Table 1-3 presents descriptive characteristics, presence of pruritus in overall and elderly patients. Overall, $37(62.7 \%)$ study participants were experiencing pruritus. The mean age of all the patients was $55.8 \pm 15.8$ years and those who developed pruritus were $54.6 \pm 16.9$ years. In addition, the mean age of the elderly patients was $67.6 \pm 7.03$ years and those with pruritus were $68.5 \pm 7$. 5 years. Table 3 shows that there was a significant relationship between presence of pruritus and the pruritus severity with the frequency of itching Grade and sleep disturbance Score among elderly $(p=0.001)$.

Figure 1 demonstrates the sensitivity analysis for the serum urea to predict pruritus among elderly chronic dialysis patients. The ROC curve showed an area under the curve (AUC) for the serum urea to predict uremic pruritus among elderly patients to be 0.700 (95\% Cl: $0.505-0.895)$ which is considered to have a good diagnostic value. The optimal cutoff value of serum urea is $119 \mathrm{mg} / \mathrm{dl}$ based on the optimal sensitivity (72.2\%) and specificity (78.6\%). It had also a higher positive predictive value (81.2\%), Negative Predictive Value (68.7\%), Positive Likelihood Ratio (3.37), Negative Likelihood Ratio (0.35) and accuracy (75\%).

Multivariate regression analysis was used to identify the factors independently associated with the development of pruritus in the overall patients as well as among elderly group (Table 4 \& 5).Male gender, hypertension, elevated serum albumin and random blood sugar were independent predictors of pruritus in patients undergoing chronic dialysis. 


\begin{tabular}{|c|c|c|c|}
\hline Variable & Value & Variable & Value \\
\hline $\begin{array}{l}\text { Age } \\
\text { (mean } \pm S D) \text { years }\end{array}$ & $55.8 \pm 15.8$ & $\begin{array}{l}\text { Intensity of pruritus } \\
\text { (Visual Analogue Scale) Score }\end{array}$ & \\
\hline Sex & & No pruritus (VAS $=0$ ) & $22(37.3 \%)$ \\
\hline Male & $41(69.5 \%)$ & Mild pruritus (VAS= 1-2) & $7(11.9 \%)$ \\
\hline Female & $18(30.5 \%)$ & Moderate pruritus (VAS= $3-6$ ) & $23(39.0 \%)$ \\
\hline Body mass index & $23.8 \pm 5.0$ & Severe pruritus (VAS $=7-8$ ) & $7(11.9 \%)$ \\
\hline Hypertension & $52(89.7 \%)$ & Sleep disturbance score & \\
\hline Diabetes mellitus & $34(58.6 \%)$ & $\begin{array}{l}\text { Sleep never disturbed } \\
\text { due to pruritus }\end{array}$ & $23(39.0 \%)$ \\
\hline Laboratory findings & & Occasionally delays falling asleep & $10(16.9 \%)$ \\
\hline Hemoglobin $(\mathrm{g} / \mathrm{dl})$ & $9.1 \pm 1.8$ & Frequent delays in falling asleep & $16(27.1 \%)$ \\
\hline Serum urea (mg/dl) & $118.7 \pm 44.6$ & $\begin{array}{l}\text { Delayed falling asleep and } \\
\text { occasionally awakes at night }\end{array}$ & $8(13.6 \%)$ \\
\hline Serum creatinine $(\mathrm{mg} / \mathrm{dl})$ & $9.7 \pm 3.5$ & $\begin{array}{l}\text { Delayed falling asleep and } \\
\text { frequently awakes at night }\end{array}$ & $2(3.4 \%)$ \\
\hline Serum albumin $(g / d l)$ & $3.9 \pm 0.5$ & Frequency of itching score & \\
\hline Serum calcium $(\mathrm{mg} / \mathrm{dl})$ & $7.8 \pm 1.4$ & No pruritus & $23(39.0 \%)$ \\
\hline Serum phosphate(mg/dl) & $6.5 \pm 2.1$ & Four short episodes (<10 min) & $19(32.2 \%)$ \\
\hline Serum random glucose (mg/dl) & $132.5 \pm 70.2$ & One long episode (>10 min) & $15(25.4 \%)$ \\
\hline Dialysis type & & Continuous pruritus & $2(3.4 \%)$ \\
\hline Hemodialysis & $47(79.7 \%)$ & Treatments & \\
\hline Peritoneal dialysis & $12(20.3 \%)$ & Anti-pruritic treatments & $39(66.1 \%)$ \\
\hline No pruritus & $22(37.3 \%)$ & Other treatments/supplements & $44(74.6 \%)$ \\
\hline Pruritus & $37(62.7 \%)$ & & \\
\hline \multicolumn{4}{|l|}{ Pruritus Localized/ Generalized } \\
\hline Localized & $18(48.6 \%)$ & & \\
\hline Generalized & 19 (51.4\%) & & \\
\hline
\end{tabular}

Table 2: Clinical characteristics, laboratory findings and treatment based on the presence of pruritus

\begin{tabular}{|l|l|l|l|}
\hline Age & $\begin{array}{c}\text { No Pruritus } \\
(\mathrm{n}=22)\end{array}$ & $\begin{array}{c}\text { Pruritus } \\
(\mathrm{n}=37)\end{array}$ & \multicolumn{1}{|c|}{ P value } \\
\cline { 1 - 3 } Sex & $57.8 \pm 13.9$ & $54.6 \pm 16.9$ & 0.46 \\
\hline Males & & & \\
\hline Females & $15(68.2 \%)$ & $26(70.3 \%)$ & 0.86 for all \\
\hline Body mass index & $7(31.8 \%)$ & $11(29.7 \%)$ & \\
\hline Hypertension & $23.6 \pm 4.2$ & $23.9 \pm 5.5$ & 0.78 \\
\hline Diabetes mellitus & $21(95.5 \%)$ & $31(86.1 \%)$ & 0.25 \\
\hline Laboratory findings & $12(54.5 \%)$ & $22(61.1 \%)$ & 0.62 \\
\hline Hemoglobin $(\mathrm{g} / \mathrm{dl})$ & & & \\
\hline Serum urea $(\mathrm{mg} / \mathrm{dl})$ & $9.2 \pm 2.1$ & $8.9 \pm 1.6$ & 0.64 \\
\hline Serum creatinine $(\mathrm{mg} / \mathrm{dl})$ & $102.4 \pm 40.3$ & $128.4 \pm 44.8$ & 0.03 \\
\hline Serum albumin $(\mathrm{g} / \mathrm{dl})$ & $9.6 \pm 4.3$ & $9.9 \pm 2.9$ & 0.76 \\
\hline Serum calcium $(\mathrm{mg} / \mathrm{dl})$ & $3.8 \pm 0.5$ & $3.9 \pm 0.5$ & 0.38 \\
\hline
\end{tabular}




\begin{tabular}{|c|c|c|c|}
\hline Serum phosphate(mg/dl) & $6.3 \pm 1.8$ & $6.7 \pm 2.2$ & 0.52 \\
\hline Serum random glucose $(\mathrm{mg} / \mathrm{dl})$ & $144.2 \pm 81.1$ & $125.5 \pm 62.9$ & 0.32 \\
\hline \multicolumn{4}{|l|}{ Dialysis type } \\
\hline Hemodialysis & $19(86.4 \%)$ & $28(75.7 \%)$ & \multirow[t]{2}{*}{0.32 for all } \\
\hline Peritoneal dialysis & $3(13.6 \%)$ & $9(24.3 \%)$ & \\
\hline \multicolumn{4}{|l|}{ Intensity of pruritus (VAS) Score } \\
\hline No pruritus (VAS $=0$ ) & $22(100 \%)$ & $0(0.0 \%)$ & \multirow[t]{4}{*}{0.001 for al } \\
\hline Mild pruritus (VAS= 1-2) & $0(0.0 \%)$ & $7(18.9 \%)$ & \\
\hline Moderate pruritus (VAS $=3-6$ ) & $0(0.0 \%)$ & $23(62.2 \%)$ & \\
\hline Severe pruritus (VAS= 7-8) & $0(0.0 \%)$ & $7(18.9 \%)$ & \\
\hline \multicolumn{4}{|l|}{ Frequency of itching Grade } \\
\hline No pruritus & $22(100 \%)$ & $1(2.7 \%)$ & \multirow[t]{4}{*}{0.001 for al } \\
\hline Four short episodes (<10 min & $0(0.0 \%)$ & $19(51.4 \%)$ & \\
\hline One long episode (>10 min) & $0(0.0 \%)$ & $15(40.5 \%)$ & \\
\hline Continuous pruritus & $0(0.0 \%)$ & $2(5.4 \%)$ & \\
\hline \multicolumn{4}{|l|}{ Sleep disturbance Score } \\
\hline Sleep never disturbed due to pruritus & $22(100 \%)$ & $1(2.7 \%)$ & \multirow[t]{5}{*}{0.001 for al } \\
\hline Occasionally delays falling asleep & $0(0.0 \%)$ & $10(27.0 \%)$ & \\
\hline Frequent delays in falling asleep & $0(0.0 \%)$ & $16(43.2 \%)$ & \\
\hline $\begin{array}{l}\text { Delayed falling asleep } \\
\text { and occasionally awakes at night }\end{array}$ & $0(0.0 \%)$ & $8(21.6 \%)$ & \\
\hline $\begin{array}{l}\text { Delayed falling asleep and } \\
\text { frequently awakes at night }\end{array}$ & $0(0.0 \%)$ & $2(5.4 \%)$ & \\
\hline \multicolumn{4}{|l|}{ Treatments } \\
\hline Anti-pruritic treatments & $18(81.8 \%)$ & $21(56.8 \%)$ & 0.04 \\
\hline Other treatments/supplements & $18(81.8 \%)$ & $26(70.3 \%)$ & 0.32 \\
\hline
\end{tabular}

Table 3: Clinical characteristics, laboratory findings and treatment among elderly based on the presence of pruritus ( $n=32$ )

\begin{tabular}{|c|c|c|c|}
\hline & $\begin{array}{l}\text { No Pruritus } \\
(n=14)\end{array}$ & $\begin{array}{c}\text { Pruritus } \\
(n=18)\end{array}$ & P value \\
\hline Age & $66.5 \pm 6.4$ & $68.5 \pm 7.5$ & 0.43 \\
\hline \multicolumn{4}{|l|}{ Sex } \\
\hline Males & $11(78.6 \%)$ & $10(55.6 \%)$ & \multirow[t]{2}{*}{0.17 for all } \\
\hline Females & $3(21.4 \%)$ & $8(44.4 \%)$ & \\
\hline Body mass index & $24.1 \pm 3.3$ & $24.9 \pm 4.2$ & 0.56 \\
\hline Hypertension & $1(7.1 \%)$ & $2(11.8 \%)$ & 0.66 \\
\hline Diabetes mellitus & $5(35.7 \%)$ & $4(23.5 \%)$ & 0.45 \\
\hline \multicolumn{4}{|l|}{ Laboratory findings } \\
\hline Hemoglobin (g/dl) & $8.7 \pm 1.8$ & $9.5 \pm 1.6$ & 0.22 \\
\hline Serum urea $(\mathrm{mg} / \mathrm{dl})$ & $96.4 \pm 35.8$ & $122.4 \pm 36.1$ & 0.05 \\
\hline Serum creatinine $(\mathrm{mg} / \mathrm{dl})$ & $8.9 \pm 4.7$ & $9.3 \pm 3.1$ & 0.77 \\
\hline Serum albumin (g/dl) & $3.7 \pm 0.4$ & $3.9 \pm 0.5$ & 0.12 \\
\hline Serum calcium (mg/dl) & $7.9 \pm 0.9$ & $7.6 \pm 1.7$ & 0.57 \\
\hline Serum phosphate(mg/dl) & $5.9 \pm 1.8$ & $6.8 \pm 2.5$ & 0.27 \\
\hline Serum random glucose $(\mathrm{mg} / \mathrm{dl})$ & $165.4 \pm 94.6$ & $142.4 \pm 86.1$ & 0.48 \\
\hline \multicolumn{4}{|l|}{ Dialysis type } \\
\hline Hemodialysis & $13(92.9 \%)$ & $17(94.4 \%)$ & \multirow[t]{2}{*}{0.85 for al } \\
\hline Peritoneal dialysis & $1(7.1 \%)$ & $1(5.6 \%)$ & \\
\hline
\end{tabular}




\begin{tabular}{|c|c|c|c|}
\hline Intensity of pruritus (VAS) Score & & & \\
\hline No pruritus (VAS $=0$ ) & $14(100 \%)$ & $0(0.0 \%)$ & \multirow[t]{4}{*}{0.001 for all } \\
\hline Mild pruritus (VAS $=1-2$ ) & $0(0.0 \%)$ & $1(5.6 \%)$ & \\
\hline Moderate pruritus (VAS $=3-6$ ) & $0(0.0 \%)$ & $11(61.1 \%)$ & \\
\hline Severe pruritus (VAS $=7-8$ ) & $0(0.0 \%)$ & $6(33.3 \%)$ & \\
\hline \multicolumn{4}{|l|}{ Frequency of itching Grade } \\
\hline No pruritus & $14(100 \%)$ & $0(0.0 \%)$ & \multirow[t]{4}{*}{0.001 for all } \\
\hline Four short episodes (<10 min & $0(0.0 \%)$ & $9(50.0 \%)$ & \\
\hline One long episode (>10 min) & $0(0.0 \%)$ & $8(44.4 \%)$ & \\
\hline Continuous pruritus & $0(0.0 \%)$ & $1(5.6 \%)$ & \\
\hline \multicolumn{4}{|l|}{ Sleep disturbance Score } \\
\hline Sleep never disturbed due to pruritus & $14(100 \%)$ & $0(0.0 \%)$ & \multirow[t]{5}{*}{0.001 for all } \\
\hline Occasionally delays falling asleep & $0(0.0 \%)$ & $4(22.2 \%)$ & \\
\hline Frequent delays in falling as leep & $0(0.0 \%)$ & $6(33.3 \%)$ & \\
\hline $\begin{array}{l}\text { Delayed falling asleep and occasionally } \\
\text { awakes at night }\end{array}$ & $0(0.0 \%)$ & $6(33.3 \%)$ & \\
\hline $\begin{array}{l}\text { Delayed falling asleep and frequently } \\
\text { awakes at night }\end{array}$ & $0(0.0 \%)$ & $2(11.1 \%)$ & \\
\hline \multicolumn{4}{|l|}{ Treatments } \\
\hline Anti-pruritic treatments & $11(78.6 \%)$ & $6(33.3 \%)$ & 0.01 \\
\hline Other treatments/supplements & $11(78.6 \%)$ & $12(66.7 \%)$ & 0.45 \\
\hline
\end{tabular}

Table 4: Severity of uremic pruritus by multivariate regression

\begin{tabular}{|l|c|c|c|c|c|}
\hline $\begin{array}{l}\text { Variable } \\
\text { (reference value) }\end{array}$ & $\beta$ & OR & \multicolumn{2}{|c|}{$95 \% \mathrm{Cl}$} & P value \\
\hline Males & 0.116 & 1.019 & -1.957 & 2.189 & 0.911 \\
\hline Age & 0.021 & 1.122 & -0.051 & 0.093 & 0.558 \\
\hline Hemoglobin & -0.066 & 0.957 & -0.582 & 0.451 & 0.799 \\
\hline Urea & 0.013 & 1.243 & -0.007 & 0.034 & 0.191 \\
\hline Creatinine & -0.070 & 0.912 & -0.358 & 0.217 & 0.624 \\
\hline Albumin & 1.426 & 1.290 & -0.532 & 3.385 & 0.149 \\
\hline Calcium & -0.229 & 0.889 & -0.820 & 0.362 & 0.439 \\
\hline Phosphorus & 0.098 & 1.077 & -0.347 & 0.544 & 0.659 \\
\hline Random blood sugar & 0.005 & 1.130 & -0.009 & 0.018 & 0.477 \\
\hline Hypertension & 0.477 & 1.051 & -2.803 & 3.758 & 0.771 \\
\hline Body Mass Index & 0.017 & 1.031 & -0.160 & 0.194 & 0.847 \\
\hline
\end{tabular}

Table 5: Severity of uremic pruritus by multivariate regression among elderly

\begin{tabular}{|l|c|c|c|c|c|}
\hline $\begin{array}{l}\text { Variable } \\
\text { (reference value) }\end{array}$ & $\beta$ & OR & \multicolumn{2}{|c|}{$95 \% \mathrm{Cl}$} & P value \\
\hline Males & 1.139 & 1.193 & -2.058 & 4.337 & 0.464 \\
\hline Hemoglobin & 0.144 & 1.083 & -0.818 & 1.107 & 0.756 \\
\hline Urea & 0.004 & 1.045 & -0.044 & 0.051 & 0.876 \\
\hline Creatinine & 0.063 & 1.083 & -0.370 & 0.496 & 0.763 \\
\hline Albumin & 2.890 & 1.593 & -1.958 & 7.737 & 0.226 \\
\hline Calcium & -0.234 & 0.899 & -1.276 & 0.809 & 0.643 \\
\hline Phosphorus & -0.014 & 0.989 & -0.944 & 0.916 & 0.976 \\
\hline Random blood sugar & 0.005 & 1.165 & -0.013 & 0.023 & 0.543 \\
\hline Hypertension & 1.285 & 1.135 & -4.156 & 6.726 & 0.626 \\
\hline Body Mass Index & 0.038 & 1.047 & -0.335 & 0.410 & 0.835 \\
\hline
\end{tabular}




\section{DISCUSSION}

Pruritus in chronic kidney disease patients is characterized by itching that is directly associated with renal failure in absence of other co-morbidities. It is one of the most frequent and distressing symptom in chronic kidney disease patients, which affects sleep, daily activities and impaired quality of life of the patients. ${ }^{8,9}$ With the increase in ageing population even in developing country such as Nepal, the prevalence of pruritus is also on rise.

The diagnosis and burden of this nuisance and frustrating symptom are often remains undetermined and under reported by treating physician. ${ }^{10}$ An international study by Rayner et $\mathrm{al}^{11}$ on 35,452 hemodialysis patients reported underestimation of the prevalence of pruritus by two-third of the medical directors and that pruritus possess major impact on professional and social life of the patients. Previously, around $50-90 \%$ of the chronic dialysis patients were affected by pruritus, but the prevalence has declined over the past decades due to improved hemodialysis techniques. The symptoms of pruritus usually begins about couple of months after the initiation of dialysis which ranges from localized to generalized itching with different intensities (mild to severe). ${ }^{12}$ The pathological mechanism of uremic pruritus is multifactorial which may involve xerosis, systemic micro inflammation, elevated Th1 to Th2 cell ratio, divalent ion abnormalities, hypervitaminosis $A$, secondary hyperparathyroidism, peripheral neuropathy, opiate receptorimbalance, neuropathic process, mastocytosis in skin either alone or in combination. Therefore, it is difficult to attribute a single factor in the pathogenesis of itching and hence the management is much challenging. ${ }^{13}$

An earlier study reported generalized pruritus in two-thirds of the hemodialysis patients and the remaining one-third had localized pruritus mainly confined to the back, face and arm with arteriovenous fistula. ${ }^{3}$ This is in contrast with the present study in which localized and generalized pruritus were reported in almost equal proportions $(48.6 \% \mathrm{Vs}$ $51.4 \%)$. Moreover, our findings are in agreement with an earlier study by Narita et al $^{12}$ which reported generalized pruritus in up to $50 \%$ of patients with chronic kidney disease. In case of generalized pruritus, various disorders related to hematology, dermatology, hepatic, endocrine, neuropsychiatry, drug allergies and other underlying malignancies should be ruled out. The severity of pruritus in chronic kidney disease patients varies from mild sporadic discomfort to severe persistent restlessness which strongly influence the quality of life of the patient. Interestingly, the skin of affected individuals remain unremarkable and often resembles with age related changes, like xerosis. ${ }^{14}$

Many larger studies have identified association of male gender with the chronic kidney disease-related pruritus. An international study on pruritus in hemodialysis patients showed higher association with males who had 1.1 times higher adjusted odds of developing pruritus. ${ }^{3}$ Similarly, other studies have identified even higher risk of male gender (OR 1.5) for pruritus. Contrarily, unadjusted results based on smaller studies did not identify association of gender with more severe pruritus.' In line with these observation, there were no significant gender differences identified either in the overall cohort as well as in the subgroup analysis of elderly patients on dialysis ( $p$ value 0.86 and 0.17 , respectively).

Uremic pruritus led to some sort of sleep disturbances in almost $61 \%$ of the patients, whereas another study by Ozen et al ${ }^{15}$ reported sleep disturbances in only $33.8 \%$ patients. In the present study, a significant relationship was observed between presence of pruritus and the pruritus severity, frequency of itching grade and sleep disturbance score among elderly.

Moreover, blood urea level was significantly higher in patients with pruritus as compared to non-pruritus group among the overall cohort as well as in the elderly group $(P=0.03$ and $P=0.05$, respectively), which was consistent with the study by $\mathrm{Hu}$ et al. $^{16}$ However, there were no significant difference in the serum levels of hemoglobin, albumin, calcium and phosphorus between pruritus and non-pruritus group in both all chronic dialysis patients as well as elderly in our study. Serum phosphate level showed association with increase in pruritus in an earlier study from Nepal by Adhikari et al $^{4}$ and Dialysis Outcomes and Practice Patterns Study (DOPPS) ${ }^{3}$ which was contrary to our findings where there was no association in all patients $(P=0.52)$ as well as in elderly $(\mathrm{P}=0.27)$.

There was no association of uremic pruritus with the predisposing factors such as age, gender, ethnicity, duration of dialysis, and etiology of renal failure. The inconsistency for findings could be attributed to the smaller sample size and relatively short duration of study observation. Therefore, a large multicenter study is warranted to include more number of hemodialysis patients together with longer follow up that will provide substantial data on the burden of pruritus and its associated factors.

In the current study, $63 \%$ of the chronic kidney disease had associated pruritus. To date, there is advancement in the standard clinical approach for patients with uremic pruritus; but still further research is needed to understand the pathophysiology and develop more reliable treatment for pruritus. $^{17}$

Improvement of symptomatic management in chronic kidney disease patients is the priority for establishing clinical practice guidelines and research. Notably, an earlier large cohort study showed that $20 \%$ of the severely affected chronic kidney disease patients did not receive treatment for pruritus which is consistent with lower treatment rates observed by other investigators. Patients with untreated pruritus were more likely to develop sleep disturbance, depression, and affect general health and impaired quality of life. ${ }^{18} \mathrm{Health}$ related quality of life of chronic dialysis patients is often compromised partially due to higher symptoms and significant impact on sleeping habit and socialization $^{19}$ which necessitates more attention and efforts to improve the holistic management approach which will be addressed in future research studies. 


\section{CONCLUSIONS}

Our findings demonstrate that higher proportion of patients undergoing chronic dialysis were diagnosed with uremic pruritus (63\%). The occurrence of pruritus showed association with frequency of itching grade and sleep disturbance score. The serum levels of urea may predict the occurrence of pruritus among elderly patients. In addition, male gender, hypertension, elevated serum albumin and random blood sugar were independent predictors of pruritus in patients undergoing chronic dialysis. Furthermore, a large multicenter study is warranted to include more number of hemodialysis patients together with long term follow-up which may provide robust information on the burden of pruritus and its associated factors to guide appropriate management among elderly.

\section{LIMITATION OF THE STUDY}

This is the unique study from western Nepal which assessed the prevalence of uremic pruritus and its associated factors in chronic dialysis patient and also focuses on elderly patients with chronic kidney disease associated pruritus. This study highlighted the patient characteristics, comorbidities, biochemical parameters, frequency of itching, sleep disturbance score and current care practice for pruritus at hospital settings.

\section{REFERENCES}

1. Lugon JR. Uremic pruritus: a review. Hemodial Int. 2005;9(2):180188. doi:10.1111/j.1492-7535.200501130.x

2. Bencini PL, Montagnino $G$, Citterio $A$, et al. Cutaneous abnormalities in uremic patients. Nephron. 1985;40(3):316-321. doi:10.1159/ 000183485

3. Pisoni RL, Wikström B, Elder SJ, et al. Pruritus in haemodialysis patients: International results from the Dialysis Outcomes and Practice Patterns Study (DOPPS). Nephrol Dial Transplant. 2006;21(12):3495-3505. doi:10.1093/ndt/gfl461

4. Adhikari L, Kayastha R, Bhatta K. Prevalence of uremic pruritus in chronic kidney patients undergoing maintenance hemodialysis at Kathmandu Medical College Teaching Hospital. J Kathmandu Med Coll 2017;5(4):124-127. https://doi.org/10.3126/jkmc.v5i4.18610.

5. Shrestha $P$, MathurM. Dermatologic manifestations in chronic kidney disease patients on hemodialysis. NJDVL 2014; 12(1):3440.https://doi.org/10.3126/njdvl.v12i1.10594

6. Narita I, Alchi B, Omori K, et al. Etiology and prognostic significance of severe uremic pruritus in chronic hemodialysis patients. Kidney Int. 2006;69(9):1626-1632. doi:10.1038/sj.ki.5000251

7. Shirazian S, Aina O, Park Y, et al. Chronic kidney disease-associated pruritus: impact on quality of life and current management challenges. Int J Nephrol Renovasc Dis. 2017;10:11-26. doi:10.2147/ IJNRD.S108045

8. Patel T, Yosipovitch G. Therapy of pruritus. Expert Opin Pharmacother. 2010;11(10):1673-1682. doi:10.1517/14656566. 2010.484420

9. Panuganti B, Tarbox M. Evaluation and management of pruritus and scabies in the elderly population. Clin Geriatr Med. 2013;29(2):479499. doi:10.1016/j.cger.2013.01.009
The potential limitations of the present study include smaller sample size and single centre study which may influence the generalizability of our findings. Secondly, most of the patientsin our cohort were on polypharmacy, and so the role of medication in chronic kidney disease associated pruritus was not addressed in much detail. Third, various aggravating and relieving factors were not taken into consideration in the present study. Finally, WBC countand presence of dry skin as causes of pruritus were not assessed in the current study.

\section{ACKNOWLEDGEMENS}

The authors would like to acknowledge all supporng staff of department of dermatology and Instutional Review Committee (IRC) of Manipal college of medical sciences, Pokhara.

\section{CONFLICT OF INTEREST}

No potential conflict of interest.

\section{FINANCIAL DISCLOSURE}

No any financial support from any agencies.

10. Weisshaar E, Matterne U, Mettang T. How do nephrologists in haemodialysis units consider the symptom of itch? Results of a survey in Germany. Nephrol Dial Transplant. 2009;24(4):1328-1330. doi:10.1093/ndt/gfn769

11. Rayner HC, Larkina M, Wang M, et al. International Comparisons of Prevalence, Awareness, and Treatment of Pruritus in People on Hemodialysis. Clin J Am Soc Nephrol. 2017;12(12):2000-2007. doi:10.2215/CJN.03280317

12. Narita I, Iguchi S, Omori K, Gejyo F. Uremic pruritus in chronic hemodialysis patients. J Nephrol. 2008;21(2):161-165..

13. Aramwit $P$, Supasyndh $O$. Uremic pruritus; its prevalence, pathophysiology and management. Suzuki, H. Update in Hemodialysis. Croatia: InTech, 2015: 19-41.doi:10.5772/59352

14. Mettang T, Kremer AE. Uremic pruritus. Kidney Int. 2015;87(4):685691. doi:10.1038/ki.2013.454

15. Ozen N, Cinar FI, Askin D, Mut D. Uremic pruritus and associated factors in hemodialysis patients: A multi-center study. Kidney Res Clin Pract. 2018;37(2):138-147. doi:10.23876/j.krcp.2018.37.2.138

16. Hu T, Wang B, Liao X, Wang S. Clinical features and risk factors of pruritus in patients with chronic renal failure. Exp Ther Med. 2019;18(2):964-971. doi:10.3892/etm.2019.7588

17. Robertson KE, Mueller BA. Uremic pruritus, American Journal of Health-System Pharmacy, 1996;53(18):2159-2170, https://doi.org/ 10.1093/ajhp/53.18.2159

18. Aresi G, Rayner HC, Hassan L, et al. Reasons for Underreporting of Uremic Pruritus in People With Chronic Kidney Disease: A Qualitative Study. J Pain Symptom Manage. 2019;58(4):578-586.e2. doi:10.1016/j.jpainsymman.2019.06.010

19. Weisbord SD, Fried LF, Arnold RM, et al. Prevalence, severity, and importance of physical and emotional symptoms in chronic hemodialysis patients. J Am Soc Nephrol. 2005;16(8):2487-2494. doi:10.1681/ASN.2005020157 